\section{Modeling Chemical Degradation of a Polymer Electrolyte Membrane and its Impact on Fuel Cell} Performance

Romain Coulon $^{1,2}$, Wolfgang. G. Bessler ${ }^{2}$ and Alejandro A. Franco

${ }^{1}$ CEA Grenoble, DRT/LITEN/DTH/Laboratory of

Components for Fuel Cells and Electrolyzers, and of

Modeling (LCPEM), 17 rue des Martyrs, F-38000 Grenoble

${ }^{2}$ German Aerospace Center (DLR), Institute of Technical

Thermodynamics, Pfaffenwaldring 38-40, D-70569 Stuttgart

E-mail: alejandro.franco@cea.fr

Materials durability in state-of-the-art polymer electrolyte membrane fuel cells (PEMFC) is one of the main shortcomings limiting the large-scale development and commercialization of this zero-emission power technology. Typical PEMFC lifetime is only around 300500 hours under some severe operating conditions representative of automotive applications [1]. Part of the loss of performance is due to a severe electrochemical degradation of the perfluorosulfonated polymer electrolyte membrane (PEM). The origin of these degradation phenomena is partly known and described in the literature [2], but still not on a way which allows predicting the associated impact on the temporal evolution (degradation) of the cell potential.

Despite numerous previous experimental works on the impact of specific PEMFC operation conditions on PEM degradation [3-4], only few modeling work predicting the evolution of the PEM transport properties and addressing the transient behavior of the PEM degradation mechanisms in interaction with other physicochemical aging phenomena have been reported [5].

Franco et al. recently proposed a multi-scale modeling framework of PEMFC electrochemical processes [6-8] that allows to understand the detailed mechanisms underlying the PEM degradation under automotive operating conditions. This approach scales up ab initio concepts into an elementary kinetic model accounting for: (i) the MEA physicochemistry at the spatial nanoscale (detailed HOR and ORR electrocatalysis, steric and electrochemical double layer effects) and microscale (ionic and reactants transfers), (ii) the intrinsic MEA nanomaterials degradation (e.g. catalyst oxidation/dissolution/ripening, carbon support corrosion, metallic ions migration and catalyst contamination by external impurities).

In this paper a microstructurally resolved model of the PEM degradation is developed, linking the elementary kinetic processes of PEM electrochemical aging with the microstructural evolution (pore size distribution, ionomer chains lengths...) and the evolution of the local physical properties $\left(\mathrm{H}_{2} / \mathrm{O}_{2} / \mathrm{N}_{2}\right.$ permeation, water diffusivity, proton conductivity).

The microstructure of the PEM is modeled as a timevariant multi-fractal object (Fig. 1). A first fractal dimension captures the micro-channels distribution and a second one, along the PEM thickness and associated to a twirled fractal object (like DNA), captures the channels shape distribution (local tortuosity).

The electrochemical degradation of the PEM is modeled on the basis of an elementary kinetic data (radical production through Fenton's reaction, radical initiation and propagation [9]).

On the basis of finite-element simulations, this model accounts for spatially-resolved transport of protons, water, $\mathrm{H}_{2}, \mathrm{O}_{2}, \mathrm{OH}, \mathrm{O}_{2} \mathrm{H}, \mathrm{H}_{2} \mathrm{O}_{2}$ as well as PEM degradation products.

The developed PEM model is coupled with Franco et al. electrode models [5-8], allowing to account for catalyst and carbon support degradation within the electrodes. By accounting for the numerical feedback between the calculated instantaneous local conditions (species concentrations etc.) and the degradation phenomena, the model allows predicting the evolution of the PEM aging and its transient impact on the MEA performance degradation (cell potential evolution). Simulations of the transient behavior of the experimental observables (e.g., electrode potential as function of demanded current) have been carried out and compared to dedicated experiments, including Fluorid Emission Rate (FER) measurements, for different operating conditions (OCV, power-cycled, stationary). As an example, Fig. 2 shows the simulated evolution of current-voltage curves for different simulated operation times. It is clearly seen that over time the fuel cell performance cell decreases, in particularly for high current densities. This is due to the decrease of PEM proton conductivity and the increase of the gas permeation coefficients.

In addition, we discuss a general sensitivity study of the PEM degradation to its initial microstructural properties, which can be useful information towards the PEM durability improvement.

Acknowledgments. This work is funded by the European Commission through the program PCRD 7, within the context of the project "DECODE".

\section{REFERENCES}

[1] S. Escribano et al, in Proc. of the $16^{\text {th }}$ World Hydrogen Energy Conference, Paper no. S19-583 (2006).

[2] V.O. Mittal et al, J. Electrochem. Soc. 154, B652 (2007).

[3] T. Xie, C.A. Hayden, Polymer, 48, 5497 (2007).

[4] C. Chen, T.F. Fuller, ECS Trans., 11 (1) 1127 (2007).

[5] A.A. Franco, S. Escribano, O. Lemaire, oral comm. in $215^{\text {th }}$ ECS meeting, San Francisco (2009).

[6] A.A. Franco et al, Fuel Cells, 7, 99 (2007).

[7] A.A. Franco, M. Gerard, J. Electrochem. Soc. 155, B367 (2008).

[8] A.A. Franco, M. Tembely, J. Electrochem. Soc., 154, B712 (2007).

[9] T.Xie, and C.A. Hayden, Polymer, 48, 5497 (2007).

[10] L. Rubatat, G. Gebel and O. Diat, Macromolecules, 37, 7772 (2004)

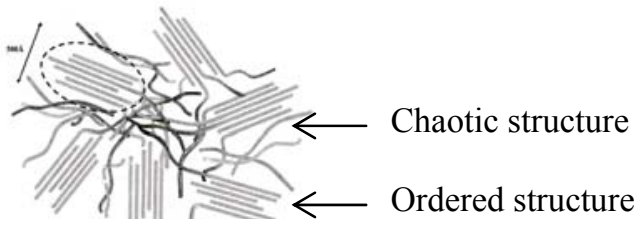

Figure 1: Schematic view of correlated polymeric aggregates domains [10]

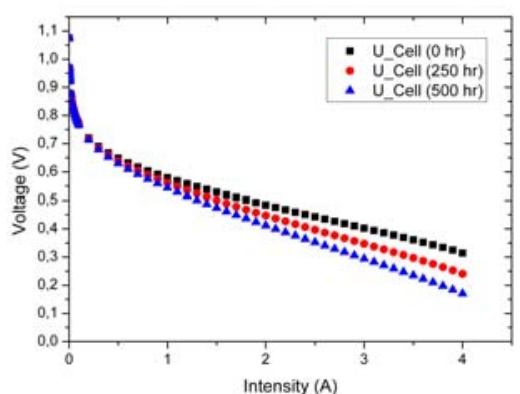

Figure 2: Calculated potential over current density at the following conditions: $\mathrm{T}_{\text {cell }}=80{ }^{\circ} \mathrm{C}, \mathrm{P}_{\mathrm{in}}=150 \mathrm{kPa}_{\mathrm{abs}}$ (An/Ca). Simulated MEA with a PFSA membrane (initial thickness $25 \mu \mathrm{m}$ ), electrode with $40 \% \mathrm{Pt} /$ Vulcan catalyst at $0.1 \mathrm{mg}_{\mathrm{Pt}} / \mathrm{cm}^{2}$ loading on anode and at $0.3 \mathrm{mg}_{\mathrm{Pt}} / \mathrm{cm}^{2}$ loading on cathode. 